\title{
Action and Interaction, Shaun Gallagher
}

Emiliano Villareal Rosales

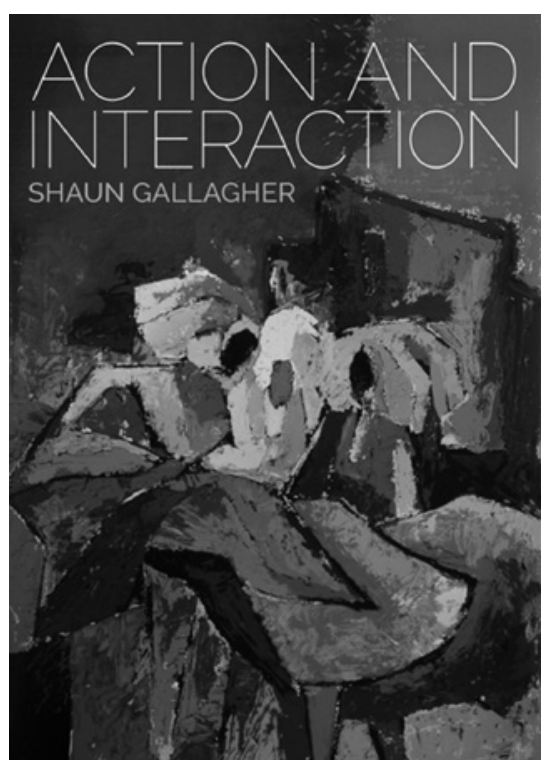

Gallagher Shaun. Action and Interaction. Oxford: Oxford University Press, 2020. 301 pp.
En su libro introductorio a la fenomenología, en las primeras páginas, el filósofo estadounidense y profesor de la Universidad de Memphis, Shaun Gallagher, manifiesta una idea bastante llamativa en referencia a su interpretación de dicho método. Señala que el punto de partida del análisis fenomenológico se ubica en la conciencia de que "nosotros, en tanto agentes que deben actuar y seres pensantes que intentan capturar lo que hacen, siempre nos encontramos ya situados en el mundo". ${ }^{1}$ Siguiendo la ruta mar-
Shaun Gallagher, Phenomenology (Nueva York: Palgrave Macmillan, 2012), 1. Todas las traducciones están hechas por el autor de esta reseña. 
cada por tal aseveración, la obra más reciente de Gallagher, Action and Interaction, se despliega como un estudio relativo al ámbito de la cognición social, combina aportaciones tanto de la fenomenología como de enfoques enactivistas. Concretamente, el libro discurre en torno a los procesos mentales intrínsecos a los fenómenos intersubjetivos, con el objetivo de modificar la perspectiva tradicional sobre la relación entre acciones e interacciones.

Un pasaje del texto especialmente ilustrativo del planteamiento de Gallagher se encuentra en una de sus tantas recuperaciones de experimentos procedentes del ámbito de los estudios del desarrollo en psicología. Ahí, el autor narra los cambios percibidos en la conducta de un bebé de tan sólo dos meses de edad, como consecuencia de su exposición a dos escenarios diferenciados por una única variable: la presencia en vivo de su madre. En un inicio, a través de un televisor, el niño es puesto en contacto con la imagen en vivo de su progenitora, de tal manera que puedan entablar un vínculo interactivo real. Hasta este punto, pese a la intervención de un componente tecnológico como la televisión, el infante se mantiene tranquilo y receptivo a los estímulos provenientes del otro lado de la pantalla. Sin embargo, una vez que, en lugar de una imagen en vivo, se le presenta una grabación de las acciones de su madre durante la primera parte de la prueba, sus reacciones pasan a denotar un estado de inconformidad y fácil distracción. ${ }^{2}$

Más allá de ahondar en los hallazgos científicos derivables de semejante experimento, lo que interesa a Gallagher es enfatizar en las implicaciones del esquema intersubjetivo subyacente. A saber, aquel en donde "el bebé responde no sólo al comportamiento expresivo de la madre (que aparece tanto en la circunstancia en vivo como en la reproducción grabada), sino también al hecho de que los movimientos de la madre son contingentes respecto a los

\footnotetext{
Para ver más acerca del experimento, consultar: Lynne Murray y Colwyn Trevarthen, "Emotional Regulations of Interactions between Two-Month-Olds and Their Mothers", en Social Perception in Infants, Tiffany Field coord. (Nueva Jersey: Ablex Publishing, 1985), 97-177
} 
propios movimientos del niño" ${ }^{3}$ Precisamente por esta razón, la primera parte de la investigación del libro está dedicada a la exposición de una serie de argumentos que justifican el pensamiento de que, desde su gestación y hasta su ejecución, las acciones acontecen en el marco de un determinado contexto relacional. Esta tesis encuentra sustento en la idea de que incluso en los momentos más tempranos del desarrollo, la vida activa se experimenta primariamente sobre una estructura en segunda persona, compuesta del involucramiento tanto del sujeto agente como de sus interlocutores. Desde esta trinchera, el autor propone interpretar la acción como cimentada en el curso de dinámicas de interacción, abierta a la contingencia del entorno e irreductible a procesos mentales restringidos a la interioridad del agente.

$\mathrm{Al}$ asumir las implicaciones derivadas de esta propuesta, Gallagher procede a internarse en el terreno de la escabrosa pero fundamental discusión acerca de la naturaleza de los fenóme- nos mentales. Sus argumentos se basan en la convicción de que la mente no puede ser entendida sin tomar en cuenta las prestaciones provenientes del campo de la interacción. De esta manera, el filósofo defiende una postura deflacionista, donde apunta a la posibilidad de una explicación de lo mental que no dependa de la apelación a estados mentales escondidos en el cerebro de un individuo. Con esto, Gallagher se ubica en clara oposición a posturas neocartesianas como la llamada teoría de la mente. En ellas, se pretende sostener la tesis de que la habilitación de las experiencias intersubjetivas requiere de la posesión de habilidades conceptuales sumamente complejas, empeñadas en descifrar los contenidos aparentemente ocultos en los estados mentales ajenos.

Finalmente, en la tercera sección de su libro, Gallagher desarrolla un movimiento al cual denomina giro crítico, con éste busca fijar los cimientos para una renovación de las ciencias cognitivas. Bajo este nuevo régimen, se in- 
tenta suscitar una ruptura con teorías limitadas a una "esfera cognitiva idealizada", ${ }^{4}$ en las que se ignoran los efectos de las circunstancias sociales mediante el estudio de simples casos abstractos. Se trata, pues, de un esfuerzo por sacar de la ingenuidad de la tercera persona a las indagaciones en torno a los diferentes niveles de la cognición humana, bajo la premisa de que "comprender a los demás y [más específicamente] comprender a los demás en nuestras interacciones cotidianas, no es algo que podamos reducir a la elaboración de explicaciones teóricas". ${ }^{5}$ A partir de este redireccionamiento, Gallagher propone fijar la atención en el plano de las prácticas comunicativas, de manera que las narraciones, definidas como el "intento por capturar la particularidad de una situación”, 6 puedan ser identificadas como uno de los ejes sobre los cuales se desdoblan las dinámicas intersubjetivas.

A mi juicio, la relevancia de una obra como Action and Interaction re- side en su capacidad para desglosar un análisis filosófico novedoso, en donde la ruta argumentativa no se encuentra sometida a pautas y restricciones externas a la trama del texto. En particular, considero que el interés de Gallagher por asumir y explorar el componente de contingencia propio de los términos en lo que refiere a la experiencia, constituye una contribución necesaria para el curso de la filosofía contemporánea. En este sentido, encuentro propuestas con múltiples potencialidades, como la configuración de una epistemología cimentada en la participación en segunda persona. Desde ahí, no sólo se genera una aproximación hacia modelos descriptivos de mayor alcance, sino que también se promueve el ejercicio de una reflexión contextualizada, tal y como se presenta en la apertura hacia una ciencia cognitiva consciente de la pertinencia de la crítica social. 


\section{Referencias}

Gallagher, Shaun, Phenomenology. Nueva York: Palgrave Macmillan, 2012. . Action and Interaction. Oxford: Oxford University Press, 2020. Murray, Lynne y Colwyn Trevarthen. "Emotional Regulations of Interactions between Two-Month-Olds and Their Mothers". En Social Perception in Infants. Coordinado por Tiffany Field, 97-177, Nueva Jersey: Ablex Publishing 1985. 